\title{
Review Article \\ Relationship between Platelet PPARs, cAMP Levels, and P-Selectin Expression: Antiplatelet Activity of Natural Products
}

\author{
Eduardo Fuentes ${ }^{1,2}$ and Iván Palomo ${ }^{1,2}$ \\ ${ }^{1}$ Department of Clinical Biochemistry and Immunohematology, Faculty of Health Sciences, \\ Programa de Investigacion de Excelencia Interdisciplinaria en Envejecimiento Saludable (PIEI-ES), Universidad de Talca, \\ 3460000 Talca, Chile \\ ${ }^{2}$ Centro de Estudios en Alimentos Procesados (CEAP), CONICYT-Regional, Gore Maule, R09I2001 Talca, Chile \\ Correspondence should be addressed to Iván Palomo; ipalomo@utalca.cl
}

Received 14 June 2013; Accepted 23 September 2013

Academic Editor: Vassya Bankova

Copyright (c) 2013 E. Fuentes and I. Palomo. This is an open access article distributed under the Creative Commons Attribution License, which permits unrestricted use, distribution, and reproduction in any medium, provided the original work is properly cited.

Platelets are no longer considered simply as cells participating in thrombosis. In atherosclerosis, platelets are regulators of multiple processes, with the recruitment of inflammatory cells towards the lesion sites, inflammatory mediators release, and regulation of endothelial function. The antiplatelet therapy has been used for a long time in an effort to prevent and treat cardiovascular diseases. However, limited efficacy in some patients, drug resistance, and side effects are limitations of current antiplatelet therapy. In this context, a large number of natural products (polyphenols, terpenoids, alkaloids, and fatty acids) have been reported with antiplatelet activity. In this sense, the present paper describes mechanisms of antiplatelet action of natural products on platelet P-selectin expression through cAMP levels and its role as peroxisome proliferator-activated receptors agonists.

\section{Introduction}

Cardiovascular diseases (CVD) result in $>19$ million deaths annually and coronary heart disease accounts for the majority of this toll. Actually a large number of victims of the disease who are apparently healthy die suddenly without prior symptoms [1]. The incidence and prevalence of CVD have increased significantly in recent years [2-4] and are regulated by both genetic and environmental factors (dyslipidemia, hypertension, smoking, diabetes, and obesity) $[5,6]$.

Platelet accumulation at sites of vascular injury is the primary event in arterial thrombosis and the activation is a critical component of atherothrombosis [7]. Thus patients with unstable complex lesions had a fivefold higher expression of the platelet activation epitope CD63 than patients with stable angina, indicating an intense thrombogenic potential [8]. Platelets also interact directly with other cells of the immune system in physiological and pathological conditions $[9,10]$. Platelet-derived P-selectin seems to contribute to atherosclerotic lesion development and arterial thrombogenesis by forming large stable platelet-leukocyte aggregates [11]. In this context, the percentage of neutrophil-platelet conjugates increased by $22 \%$ in patients with unstable angina pectoris [12]. Also platelets can be directly involved in the plaque unstable by the production and release of proinflammatory molecules, including a variety of cytokines, such as TGF- $\beta$, IL- $1 \beta$, and SCD40L, and chemokines, such as CXCL7, CXCL4, CXCL4L1, CCl5, CXCL1, CXCL8, CXCL5, CXCL12, CCL2, and CCL3 $[13,14]$.

The antiplatelet therapy has been used for a long time in an effort to prevent and treat CVD $[15,16]$. However, limited efficacy in some patients, drug resistance, and side effects are limitations of current antiplatelet therapy $[17,18]$. Therefore, there is much room for further improvement of antiplatelet treatment and search of novel antiplatelet agents with increased efficacy and safety profile. In this context, a large number of natural products (polyphenols, terpenoids, alkaloids, and fatty acids, among others) have been reported with an inhibitory activity on platelets function [19].

Interestingly, some natural compounds consumed regularly in the diet may have protective effects in primary and secondary prevention of CVD [20,21]. In this context, a great deal of interest has been paid by consumers towards natural bioactive compounds as functional ingredients in diets due 
to their various beneficial health effects [22-25]. Natural bioactive compounds from fruit, vegetables, beverages, and grass among others have antiplatelet effects and may thus affect the development of CVD [26].

In this sense, the present paper describes mechanisms of antiplatelet action of natural products by PPARs signaling pathway and inhibit of platelet P-selectin expression through of cAMP.

\section{Regulation of Platelet cAMP Levels by PPARs}

The PPARs consist of three nuclear receptor isoforms $(\gamma, \beta / \delta$, and $\alpha$ ) [27]. PPARs are key regulators of metabolic syndrome and play an important role in the processes that govern chronic inflammatory diseases $[28,29]$. Thus PPARs remain attractive therapeutic targets for the development of drugs used in the treatment of chronic inflammatory diseases such as atherosclerosis [30]. PPAR- $\delta$ antagonizes multiple proinflammatory pathways [31] and is pivotal to control the program for fatty acid oxidation in the skeletal muscle [32].

PPARs modulate atherosclerosis development by acting at both metabolic and vascular levels [33]. Thus PPARs activation is a key mechanism for improving cardiovascular function resulting from weight loss [34-36]. PPARs are expressed in human platelets [37]. In this context, PPARs appear to play a major role in the regulation of atherogenesis by countering the inflammation-provoking action of platelet adhesion and activation [38]. The antiplatelet activity of statins and fibrates on platelet function is mediated by PPARs activation via a novel mechanism that involves the inhibition of protein kinase- $\alpha$ (PKC- $\alpha$ ) [39]. In addition, statins by increasing both cAMP as well as cGMP pathways could inhibit platelet activation [39]. cAMP increased by PPAR activation is due to the repression of $\mathrm{PKC}$ that allows greater activity of adenylyl cyclase (ATP to cAMP) [40, 41]. Meanwhile, cAMPinduced inhibition of platelet $\mathrm{P}$-selectin expression is through activation of protein kinase A (PKA) [42].

\section{Relationship between cAMP Levels and Platelet P-Selectin Expression}

It has been shown that cAMP and cGMP-dependent protein kinases not only inhibit platelet pathways leading to activation and aggregation, but also those resulting in enhanced surface expression of protein ligands involved in inflammation [43]. Also, $\mathrm{Ca}^{2+}$ in human platelets is directly downregulated by cGMP and cAMP by a mechanism involving the inhibition of cytoskeletal reorganization via the activation of protein tyrosine phosphatases [44].

Moreover, platelet shape change can be antagonized by PKA (cAMP-dependent) activation but not by protein kinase $\mathrm{G}$ (PKG) (cGMP-dependent), which may occur with particular efficiency by the formation of a local compartment of cAMP through the inhibition of phosphodiesterase-3 (PDE3) [45]. In fact, activation/phosphorylation of PDE3 via Akt signaling pathway participates in regulating cAMP during thrombin activation of platelets [46]. Together, these results indicate that CAMP is persistently formed in platelets [47].

cAMP-induced inhibition of platelet P-selectin expression is, in large part, mediated through the activation of PKA [42]. While P-selectin expression was found to be independent of mitogen-activated protein kinase (MAPK) activation, since it was not inhibited by specific MAPK inhibitors [43]. Inhibition of ADP-induced P-selectin expression and platelet-leukocyte conjugate formation was inhibited by clopidogrel and AR-C69931MX but not by aspirin [48, 49]. Prolonged cyclooxygenase-2 (COX-2) inhibition attenuates C-reactive protein and IL-6, but does not modify P-selectin [50]. ARC69931MX and clopidogrel by cAMP levels can inhibit human platelet aggregation through the activation of a separate $\mathrm{G}$ protein-coupled pathway (presumably involving $\mathrm{Gs}$ ) and platelet P2Y12 receptor, respectively [51, 52]. Andersen et al. showed that levels of soluble P-selectin were significantly higher in aspirin responders and nonresponders [53]. Despite the above, measurement of circulating P-selectin has been suggested for remote testing of platelet function in patients treated with clopidogrel and aspirin [54].

\section{Mechanism of Antiplatelet Action of Natural Products}

In the context of atherosclerosis CVD, platelets can adhere to endothelial cells and leukocytes and contribute to vascular inflammation and thrombosis formation $[55,56]$. In this sense, the inhibition of the platelet function has been used for long time in an effort to prevent and treat CVD [57]. However, limited efficacy in some patients, drug resistance, and side effects are limitations of current antiplatelet therapy [17, 18]. Moreover, epidemiological studies have provided evidence of a protective role of healthy diets in the prevention of CVD $[58,59]$.

The consumption of a diet containing $30 \%$ green and yellow vegetables results in a substantial inhibition of atherosclerosis progression [60]. Preliminary studies have demonstrated the platelet antiaggregation activity of fruit (red grapes, strawberries, kiwis, and pineapples) and vegetables (garlic, onions, green onions, melons, and tomatoes) [61, 62]. In this context, consuming two or three kiwi fruits per day for 28 days reduces platelet aggregation induced by collagen and ADP [63]. Strawberries are likely to exert significant protective effects in thromboembolic-related disorders by inhibiting platelet aggregation $[64,65]$. Organo sulfur compounds in onion extracts are formed following the lysis of the S-alk(en)yl-L-cysteine sulfoxides by alliinase. These compounds inhibit the aggregation of human blood platelets and offer the potential for positive cardiovascular health benefits [66]. The raw form of garlic and some of its preparations are widely recognized as antiplatelet agents that may contribute to the prevention of CVD. Antithrombotic activities of garlic have been demonstrated by blood fibrinolytic and coagulation systems, and inhibition of platelet aggregation [67]. With respect to platelet function, allicin and thiosulfinates are responsible for in vitro antiaggregatory activity from garlic [68]. Furthermore, recently galactolipid and a phytosterol 
from garlic were identified as exhibiting an inhibitory action on ADP-induced aggregation in human blood platelets [69].

In fact, a large number of natural products have been reported with apparent inhibitory activity on human platelets and each constituent may possess multiply targets, and they may exert pleiotropic and synergistic effects (Table 1) [70-72].

4.1. Antiplatelet Activity of Natural Products by PPARs. Due to high levels of toxicity associated with the first generation of drugs, there is renewed search for newer PPAR drugs that exhibit better efficacy but lesser toxicity [110]. Moreover, there has been a definite increase in the consumption of fruits and vegetables, due to the possible health benefits associated with these bioactive components $[74,111]$. Thus, dietary components that act as ligands of PPARs include dietary lipids such as n-3 and n-6 fatty acids and their derivatives, polyphenols, and terpenoids, among others [112-114] (Table 2).

In this sense, the present paper describes the mechanism of antiplatelet action of natural products as PPARs agonists and increased of intraplatelet levels of cAMP. As shown in Figure 1, the mechanism of antiplatelet action by natural products PPARs agonists is mediated by the following signaling pathways: (i) inhibition of PCK- $\alpha$ /increased of cAMP levels/stimulation of PKA (increased of cAMP levels), (ii) stimulation of Akt/NOS/NO/PKG (increased of cGMP levels), and (iii) inhibition of cyclooxygenase-1 (COX-1), thromboxane A2 (TXA2), and $\mathrm{Ca}^{2+}$ mobilization.

Magnolol is the major bioactive constituent of Magnolia officinalis (2-11\% of the bark's dry weight) $[115,116]$. Magnolol could improve insulin sensitivity through the activation of PPAR- $\gamma$ [117]. Also Magnolol presents antiplatelet activity by PPAR- $\beta / \gamma$ activation with upregulation of Akt/NOS/NO/ cGMP/PKG cascade and suppression of PKC- $\alpha$ and COX-1 and $\mathrm{Ca}^{2+}$ mobilization [96].

Linolenic acid impairs arterial thrombus formation, tissue factor expression, and platelet activation and thereby represents an attractive nutritional intervention with direct dual antithrombotic effects [118]. These effects could be because both oleic and linoleic acids are PPARs agonists [119]. Meanwhile $\alpha$-lipoic acid is PPAR- $\alpha / \gamma$ agonist and the mechanism of action involves the inhibition of $\mathrm{Ca}^{2+}$ mobilization, TXA2, PKC- $\alpha$, and COX-1 expression, and elevation of cAMP levels $[104,105]$.

$\alpha$ - and $\gamma$-tocopherols have been shown to activate PPAR- $\gamma$ expression and $\gamma$-tocopherol is a better modulator of PPAR$\gamma$ expression than $\alpha$-tocopherol $[106,107]$. In this context, $\alpha$-tocopherol inhibits platelet aggregation through a PKCdependent mechanism, which may explain a decrease in the expression of P-selectin and interactions platelet-mononuclear cells ex vivo $[108,109]$.

Curcumin, the major component of food spice turmeric (Curcuma longa), inhibits platelet aggregation induced by PAF and arachidonic acid with inhibitory effects on TXA2 and $\mathrm{Ca}^{2+}$ mobilization and also prevents the adhesion of platelets to brain microvascular endothelial cells [84-86]. The beneficial effect of curcumin on platelet activation appears to be mediated by the upregulation of PPAR- $\gamma$ [87].

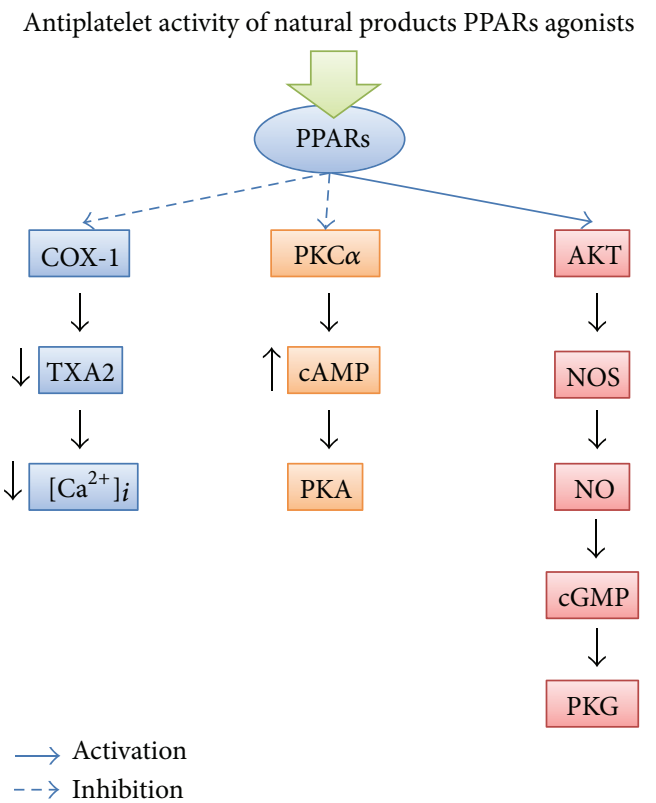

FIGURE 1: Mechanism of antiplatelet action by natural products on PPARs. cAMP $=$ cyclic adenosine monophosphate; $\mathrm{PKA}=$ protein kinase $\mathrm{A} ; \mathrm{TXA} 2$ = thromboxane $\mathrm{A} 2 ; \mathrm{PKC}=$ protein kinase $\mathrm{C}$; PLC = phospholipase; $\mathrm{COX}-1=$ cyclooxygenase-1; PPARs = peroxisome proliferator-activated receptors; $\mathrm{AKT}=$ also known as protein kinase $\mathrm{B} ; \mathrm{NO}=$ nitric oxide; $\mathrm{cGMP}=$ cyclic guanosine monophosphate; $\mathrm{PKG}=$ protein kinase $\mathrm{G} ; \mathrm{NOS}=$ nitric oxide synthase.

4.2. Antiplatelet Activity of Natural Products by CAMP Levels. Here we describe one possible mechanism of action of natural products on platelet P-selectin expression through cAMP.

The natural products caffedymine (clovamide-type phenylpropenoic acid amide found in cocoa), N-caffeoyl tyramine, $\mathrm{N}$-feruloyl tyramine, 5-caffeoylquinic acid, caffeic acid, and gallic acid were able to suppress P-selectin expression on platelets and were found to be very potent compounds able to inhibit COX-1 and 2 enzymes [73, 78, 81, 120-122]. Moreover, previous studies indicate that caffedymine and $\mathrm{N}$ caffeoyl tyramine inhibit P-selectin expression by increasing cAMP through beta-2 adrenoceptors [79, 80, 123]. Gallic acid, in a concentration-dependent manner, prevents the elevation of intracellular calcium and attenuate phosphorylation of PKC $\alpha /$ p38 MAPK and Akt/GSK $3 \beta$ on platelets stimulated by the stimulants ADP or U46619 [70]. Based on the function of other cell (mast cells), the mode of action of gallic acid is likely related with the elevation of the intracellular cAMP level by the inhibition of the CAMP phosphodiesterase [124].

Adenosine is another natural product with antiplatelet activity [74, 75]. Adenosine through G-protein linked receptors to activate adenylate cyclase and increase cellular cAMP levels, showing the inhibition of platelet P-selectin expression $[76,77]$. However, chlorogenic acid, an antiplatelet compound, presented increase of cAMP and cGMP levels and strong inhibition of COX-1 [125] and COX-2 [126] but did not have effect on P-selectin expression [127].

Moreover, sanguinarine, alkaloid present in the root of Sanguinaria canadensis and Poppy fumaria species, is a potent antiplatelet agent, which activates adenylate cyclase with 


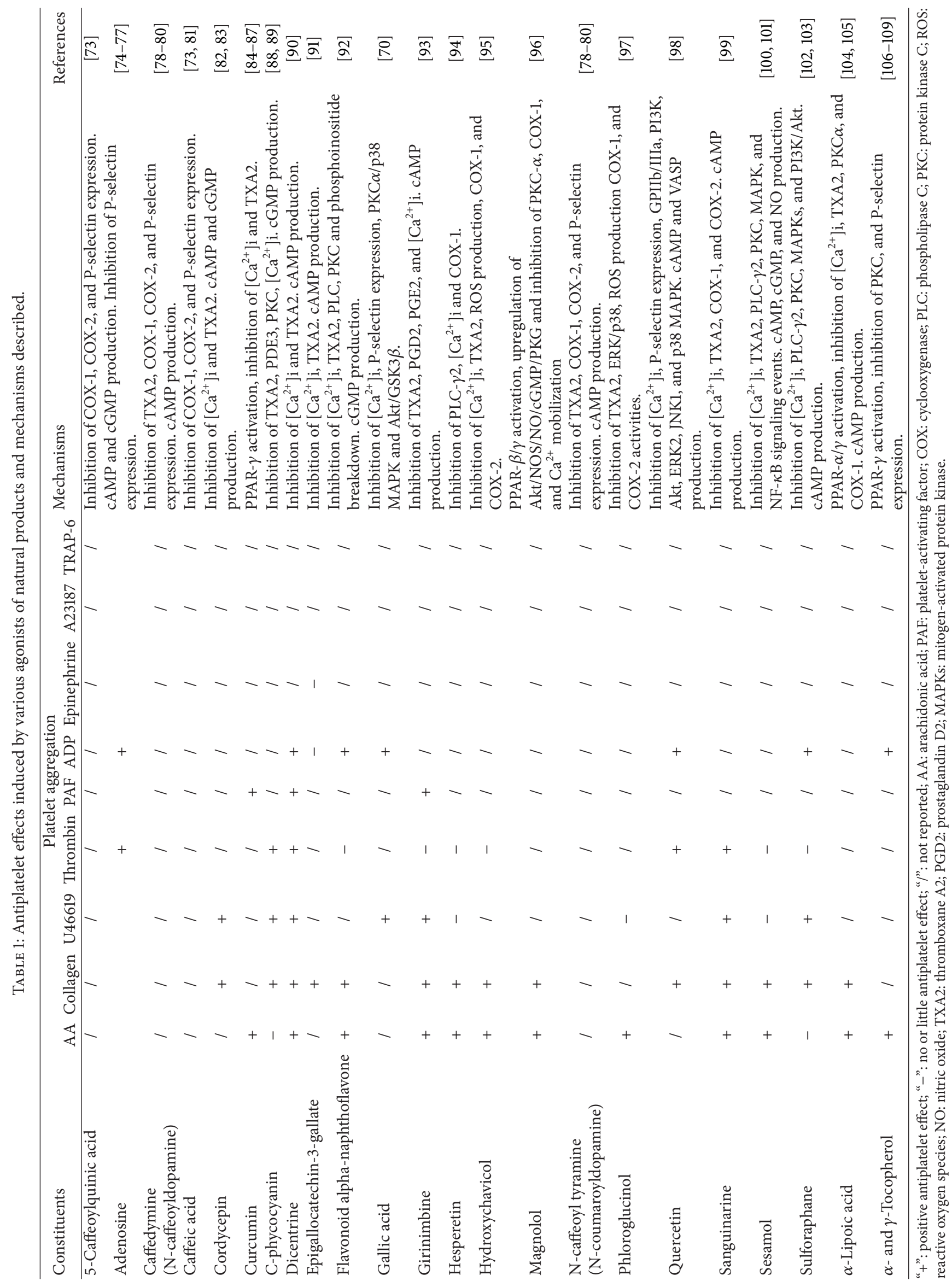


TABLE 2: Natural products PPARs agonists.

\begin{tabular}{l}
\hline PPAR- $\alpha$ \\
Catalposide \\
Berberine \\
Astaxanthin \\
9-Oxo-octadecadienoic acid \\
PPAR- $\gamma$ \\
Artepillin C \\
Kaempferol \\
20S-protopanaxatriol \\
Apigenin \\
Quercetin \\
6-Shogaol \\
Chrysin \\
(-)-catechin \\
Harmine \\
3-Acetyl oleanolic acid \\
9S,13R-12-oxo-phytodienoic acid \\
Auraptene \\
Oleic acid \\
PPAR- $\alpha / \gamma$ \\
Cyanidin \\
Vaccenic acid
\end{tabular}

cAMP production, inhibits platelet $\mathrm{Ca}^{2+}$ mobilization and TXA2 production as well as suppresses COX-1 enzyme activity (whereas its effect on COX-2 activity was minimal) [99]. Similar antiplatelet effect had girinimbine that presented the inhibition of COX activity and elevation of the cAMP level [93].

Being increased of intraplatelet levels of $\mathrm{Ca}^{2+}$ involves phosphorylation of both pleckstrin $(47 \mathrm{kDa})$ and myosin light chain $(20 \mathrm{kDa})$ via $\mathrm{Ca}^{2+}$-dependent $\mathrm{PKC}$ and $\mathrm{Ca}^{2+} /$ calmodulin-dependent protein kinase (CaM-PK), respectively. The phosphorylation of these proteins participates in the release of platelet aggregation factors such as serotonin and ADP $[128,129]$. In this context, the effect of cordycepin on platelet aggregation might be associated with the inhibition of phosphorylation of these proteins to suppress the release of serotonin and ADP out of dense body in platelets, which is associated with the inhibition of $\mathrm{Ca}^{2+}$ mobilization by cordycepinelevated cAMP $[82,83]$. Whereas the ODQ (NO-sensitive guanylyl cyclase inhibitor) did not alter the cordycepininduced upregulation of cGMP, the adenylyl cyclase inhibitor SQ22536 completely blocked the cAMP enhancement mediated by cordycepin [82]. Sulforaphane possesses potent antiplatelet activity, which may initially activate adenylate cyclase/cAMP, followed by inhibiting intracellular signals (such as the PI3-kinase/Akt and PLC $\gamma 2$-PKC-p47 cascades) [102, 103]. Furthermore epigallocatechin-3-gallate increases cAMP via adenylate cyclase activation and subsequently phosphorylates VASP-Ser-157 through A-kinase activation to inhibit $\mathrm{Ca}^{2+}$ mobilization and TXA2 production on collageninduced platelet aggregation [91]. Sesamol possesses potent antiplatelet activity, which may involve the activation of the cAMP-eNOS/NO-cGMP pathway, resulting in the inhibition of the PLC $\gamma 2$-PKC-p38MAPK-TXA2 cascade [100].
Also, sesamol activates cAMP-PKA signaling, followed by the inhibition of the NF- $\kappa$ B-PLC-PKC cascade. The inhibition of NF- $\kappa \mathrm{B}$ which interferes with platelet function may have a great impact when these types of drugs are considered for the treatment of cancer and various inflammatory diseases [101]. The inhibition of platelet aggregation by $\alpha$-lipoic acid is mediated by PPAR $\alpha / \gamma$-dependent processes, which involve interaction with PKC and COX-1, increase of cAMP formation, and inhibition of intracellular $\mathrm{Ca}^{2+}$ mobilization [104] However, the effects of $\alpha$-lipoic acid on the above platelet responses were markedly reversed by the addition of $2^{\prime} 5^{\prime}$ ddAdo, an adenylate cyclase inhibitor [105]. Meanwhile, quercetin-mediated antiplatelet activity involves PI3K/Akt inactivation, cAMP elevation, and VASP stimulation that, in turn, suppresses MAPK phosphorylations [98]. Intraplatelet cAMP production was quickly increased by quercetin stimulation and probably through the adenylate cyclase signaling pathway [130].

According to natural products as caffedymine, N-caffeoyl tyramine, quercetin, and adenosine, which increase the intraplatelet cAMP levels and inhibit platelet P-selectin expression. It is possible to consider that those natural products (sanguinarine, $\alpha$-Lipoic acid, sesamol, sulforaphane, epigallocatechin-3-gallate, and cordycepin) which increase the intraplatelet cAMP levels and lose their antiplatelet activity after adenylate cyclase blockaded would be able to inhibit platelet P-selectin expression. Even only an increase in the intraplatelet cAMP Levels may establish that dicentrine and girinimbine could inhibit P-selectin expression. Thus, the relationship between cAMP levels and P-selectin expression is because cAMP via the activation of PKA is capable of inhibiting platelet P-selectin expression [42, 77]. Furthermore, natural products that inhibited platelet aggregation stimulated by ADP and collagen with increased of cAMP levels is because cAMP downregulates P2Y1R expression [131] and GPVI-maintained in a monomeric form on resting platelets [132].

Finally, it is possible to establish that natural products that show antiplatelet activity by increasing levels of cAMP are able to inhibit platelet-leukocyte interactions through P-selectin inhibition (Figure 2). This makes it possible to consider that natural products in addition to platelet function inhibitors are compounds capable of preventing atherothrombosis/atheroinflammation.

\section{Conclusions}

According to this paper it is possible to establish that the antiplatelet activity by PPARs agonist and increased cAMP levels are not defined by one specific group of bioactive compounds. Also the data presented in this paper demonstrate that natural products with antiplatelet activity through of increase cAMP levels are able to inhibit the platelet-leukocyte interactions in atheroinflammation.

\section{Conflict of Interests}

The authors report no conflict of interests. 


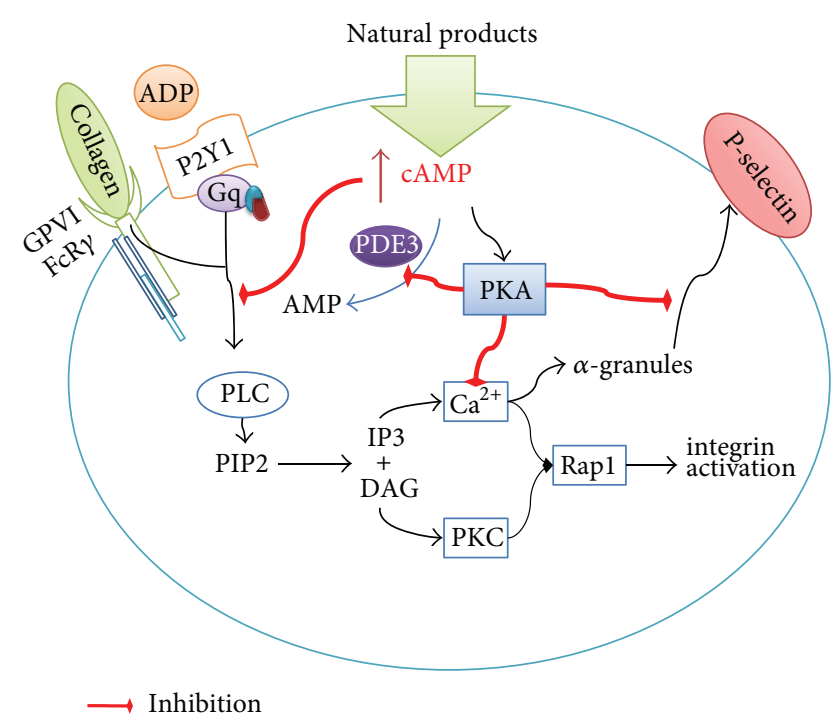

FIGURE 2: Mechanism of antiplatelet action of natural products by cAMP levels. PDE3: phosphodiesterase-3; PKA: protein kinase A; PLC: phospholipase; DAG: diacylglycerol; IP3: inositol trisphosphate; PIP2: phosphatidylinositol 4,5-bisphosphate; PKC: protein kinase C; PSGL-1: P-selectin glycoprotein ligand-1.

\section{Acknowledgments}

This work was funded by CONICYT REGIONAL/GORE MAULE/CEAP/R09I2001, Programa de Investigación de Excelencia Interdisciplinaria en Envejecimiento Saludable (PIEI-ES), and supported by grant no. 1130216 (I.P., M.G., R.M., M.A., J.C.) from Fondecyt, Chile.

\section{References}

[1] M. Naghavi, P. Libby, E. Falk et al., "From vulnerable plaque to vulnerable patient: a call for new definitions and risk assessment strategies-part I," Circulation, vol. 108, no. 14, pp. 1664-1672, 2003.

[2] "WHO publishes definitive atlas on global heart disease and stroke epidemic," Indian Journal of Medical Sciences, vol. 58, pp. 405-406, 2004.

[3] H. A. Swartz and B. L. Rollman, "Managing the global burden of depression: lessons from the developing world," World Psychiatry, vol. 2, pp. 162-163, 2003.

[4] I. F. Palomo, G. I. Torres, M. A. Alarcón, P. J. Maragaño, E. Leiva, and V. Mujica, "High prevalence of classic cardiovascular risk factors in a population of university students from South Central Chile," Revista Espanola de Cardiologia, vol. 59, no. 11, pp. 1099-1105, 2006.

[5] K. S. Reddy and S. Yusuf, "Emerging epidemic of cardiovascular disease in developing countries," Circulation, vol. 97, no. 6, pp. 596-601, 1998.

[6] M. E. Marenberg, N. Risch, L. F. Berkman, B. Floderus, and U. De Faire, "Genetic susceptibility to death from coronary heart disease in a study of twins," New England Journal of Medicine, vol. 330, no. 15, pp. 1041-1046, 1994.

[7] D. D. Wagner and P. C. Burger, "Platelets in inflammation and thrombosis," Arteriosclerosis, Thrombosis, and Vascular Biology, vol. 23, no. 12, pp. 2131-2137, 2003.
[8] E. Y. Chakhtoura, F. E. Shamoon, J. I. Haft, G. R. Obiedzinski, A. J. Cohen, and R. M. Watson, "Comparison of platelet activation in unstable and stable angina pectoris and correlation with coronary angiographic findings," American Journal of Cardiology, vol. 86, no. 8, pp. 835-839, 2000.

[9] P. A. Da Costa Martins, J. M. Van Gils, A. Mol, P. L. Hordijk, and J. J. Zwaginga, "Platelet binding to monocytes increases the adhesive properties of monocytes by up-regulating the expression and functionality of $\beta 1$ and $\beta 2$ integrins," Journal of Leukocyte Biology, vol. 79, no. 3, pp. 499-507, 2006.

[10] P. Da Costa Martins, N. Van Den Berk, L. H. Ulfman, L. Koenderman, P. L. Hordijk, and J. J. Zwaginga, "Plateletmonocyte complexes support monocyte adhesion to endothelium by enhancing secondary tethering and cluster formation," Arteriosclerosis, Thrombosis, and Vascular Biology, vol. 24, no. 1, pp. 193-199, 2004.

[11] P. C. Burger and D. D. Wagner, "Platelet P-selectin facilitates atherosclerotic lesion development," Blood, vol. 101, no. 7, pp. 2661-2666, 2003.

[12] P. B. Patel, S. E. Pfau, M. W. Cleman et al., "Comparison of coronary artery specific leukocyte-platelet conjugate formation in unstable versus stable angina pectoris," American Journal of Cardiology, vol. 93, no. 4, pp. 410-413, 2004.

[13] E. Galliera, M. M. Corsi, and G. Banfi, "Platelet rich plasma therapy: inflammatory molecules involved in tissue healing," Journal of Biological Regulators \& Homeostatic Agents, vol. 26, pp. 35S-42S, 2012.

[14] Q. E. Fuentes, Q. F. Fuentes, V. Andres, O. M. Pello, J. F. de Mora, and G. I. Palomo, "Role of platelets as mediators that link inflammation and thrombosis in atherosclerosis," Platelets, vol. 24, pp. 255-262, 2013.

[15] B. Collins and C. Hollidge, "Antithrombotic drug market. Market indicators," Nature Reviews Drug Discovery, vol. 2, no. 1, pp. 11-12, 2003.

[16] I. Palomo, C. Toro, and M. Alarcón, "The role of platelets in the pathophysiology of atherosclerosis (Review)," Molecular Medicine Reports, vol. 1, no. 2, pp. 179-184, 2008.

[17] N. E. Barrett, L. Holbrook, S. Jones et al., "Future innovations in anti-platelet therapies," British Journal of Pharmacology, vol. 154, no. 5, pp. 918-939, 2008.

[18] N. C. Raju and J. W. Eikelboom, "The aspirin controversy in primary prevention," Current Opinion in Cardiology, vol. 27, pp. 499-507, 2012.

[19] G. Vilahur and L. Badimon, "Antiplatelet properties of natural products," Vascular Pharmacology, 2013.

[20] R. Estruch, E. Ros, J. Salas-Salvado et al., "Primary prevention of cardiovascular disease with a Mediterranean diet," New England Journal of Medicine, vol. 368, pp. 1279-1290, 2013.

[21] M. De Lorgeril, S. Renaud, N. Mamelle et al., "Mediterranean alpha-linolenic acid-rich diet in secondary prevention of coronary heart disease," The Lancet, vol. 343, no. 8911, pp. 1454-1459, 1994.

[22] L. Das, E. Bhaumik, U. Raychaudhuri, and R. Chakraborty, "Role of nutraceuticals in human health," Journal of Food Science and Technology, vol. 49, pp. 173-183, 2012.

[23] T.-S. Voa and K. Se-Kwon, "Fucoidans as a natural bioactive ingredient for functional foods," Journal of Functional Foods, vol. 5, pp. 16-27, 2013.

[24] J. C. Griffiths, D. R. Abernethy, S. Schuber, and R. L. Williams, "Functional food ingredient quality: opportunities to improve public health by compendial standardization," Journal of Functional Foods, vol. 1, no. 1, pp. 128-130, 2009. 
[25] E. Fuentes, O. Forero-Doria, G. Carrasco et al., "Effect of tomato industrial processing on phenolic profile and antiplatelet activity," Molecules, vol. 18, pp. 11526-11536, 2013.

[26] L. M. Ostertag, N. O’Kennedy, G. W. Horgan, P. A. Kroon, G. G. Duthie, and B. de Roos, "In vitro anti-platelet effects of simple plant-derived phenolic compounds are only found at high, nonphysiological concentrations," Molecular Nutrition and Food Research, vol. 55, no. 11, pp. 1624-1636, 2011.

[27] L. A. Moraes, L. Piqueras, and D. Bishop-Bailey, "Peroxisome proliferator-activated receptors and inflammation," Pharmacology and Therapeutics, vol. 110, no. 3, pp. 371-385, 2006.

[28] W. Ahmed, O. Ziouzenkova, J. Brown et al., "PPARs and their metabolic modulation: new mechanisms for transcriptional regulation?" Journal of Internal Medicine, vol. 262, no. 2, pp. 184-198, 2007.

[29] E. Fuentes, F. Fuentes, G. Vilahur, L. Badimon, and I. Palomo, "Mechanisms of chronic state of inflammation as mediators that link obese adipose tissue and metabolic syndrome," Mediators of Inflammation, vol. 2013, Article ID 136584, 11 pages, 2013.

[30] C. Duval, G. Chinetti, F. Trottein, J.-C. Fruchart, and B. Staels, "The role of PPARs in atherosclerosis," Trends in Molecular Medicine, vol. 8, no. 9, pp. 422-430, 2002.

[31] G. D. Barish, A. R. Atkins, M. Downes et al., "PPAR $\delta$ regulates multiple proinflammatory pathways to suppress atherosclerosis," Proceedings of the National Academy of Sciences of the United States of America, vol. 105, no. 11, pp. 4271-4276, 2008.

[32] T. Tanaka, J. Yamamoto, S. Iwasaki et al., "Activation of peroxisome proliferator-activated receptor $\delta$ induces fatty acid $\beta$-oxidation in skeletal muscle and attenuates metabolic syndrome," Proceedings of the National Academy of Sciences of the United States of America, vol. 100, no. 26, pp. 15924-15929, 2003.

[33] H. Duez, J.-C. Fruchart, and B. Staels, "PPARs in inflammation, atherosclerosis and thrombosis," Journal of Cardiovascular Risk, vol. 8, no. 4, pp. 187-194, 2001.

[34] S. Kersten, B. Desvergne, and W. Wahli, "Roles of PPARS in health and disease," Nature, vol. 405, no. 6785, pp. 421-424, 2000 .

[35] H. Inoue, X.-F. Jiang, T. Katayama, S. Osada, K. Umesono, and S. Namura, "Brain protection by resveratrol and fenofibrate against stroke requires peroxisome proliferator-activated receptor $\alpha$ in mice," Neuroscience Letters, vol. 352, no. 3, pp. 203-206, 2003.

[36] W. Verreth, D. De Keyzer, M. Pelat et al., "Weight loss-associated induction of peroxisome proliferator-activated receptor- $\alpha$ and peroxisome proliferator-activated receptor- $\gamma$ correlate with reduced atherosclerosis and improved cardiovascular function in obese insulin-resistant mice," Circulation, vol. 110, no. 20, pp. 3259-3269, 2004.

[37] F. Akbiyik, D. M. Ray, K. F. Gettings, N. Blumberg, C. W. Francis, and R. P. Phipps, "Human bone marrow megakaryocytes and platelets express $\operatorname{PPAR} \gamma$, and PPAR $\gamma$ agonists blunt platelet release of CD40 ligand and thromboxanes," Blood, vol. 104, no. 5, pp. 1361-1368, 2004.

[38] D. M. Ray, S. L. Spinelli, J. J. O’Brien, N. Blumberg, and R. P. Phipps, "Platelets as a novel target for PPAR $\gamma$ ligands: implications for inflammation, diabetes, and cardiovascular disease," BioDrugs, vol. 20, no. 4, pp. 231-241, 2006.

[39] F. Y. Ali, P. C. J. Armstrong, A.-R. A. Dhanji et al., "Antiplatelet actions of statins and fibrates are mediated by PPARs," Arteriosclerosis, Thrombosis, and Vascular Biology, vol. 29, no. 5, pp. 706-711, 2009.
[40] L. Levesque and S. T. Crooke, "Depletion of protein kinase C- $\alpha$ by antisense oligonucleotides alters beta-adrenergic function and reverses the phorbol ester-induced reduction of isoproterenol-induced adenosine $3^{\prime}-5^{\prime}$-cyclic monophosphate accumulation in murine Swiss 3T3 fibroblasts," Journal of Pharmacology and Experimental Therapeutics, vol. 287, no. 1, pp. 425434, 1998.

[41] F. Y. Ali, M. G. Hall, B. Desvergne, T. D. Warner, and J. A. Mitchell, "PPAR $\beta / \delta$ agonists modulate platelet function via a mechanism involving PPAR receptors and specific association/ repression of PKC $\alpha$-brief report," Arteriosclerosis, Thrombosis, and Vascular Biology, vol. 29, no. 11, pp. 1871-1873, 2009.

[42] D. Libersan, G. Rousseau, and Y. Merhi, "Differential regulation of P-selectin expression by protein kinase $\mathrm{A}$ and protein kinase G in thrombin-stimulated human platelets," Thrombosis and Haemostasis, vol. 89, no. 2, pp. 310-317, 2003.

[43] U. R. Schwarz, A. L. Kobsar, M. Koksch, U. Walter, and M. Eigenthaler, "Inhibition of agonist-induced p42 and p38 mitogen-activated protein kinase phosphorylation and CD40 ligand/P-selectin expression by cyclic nucleotide-regulated pathways in human platelets," Biochemical Pharmacology, vol. 60, no. 9, pp. 1399-1407, 2000.

[44] J. A. Rosado, T. Porras, M. Conde, and S. O. Sage, "Cyclic nucleotides modulate store-mediated calcium entry through the activation of protein-tyrosine phosphatases and altered actin polymerization in human platelets," Journal of Biological Chemistry, vol. 276, no. 19, pp. 15666-15675, 2001.

[45] B. O. Jensen, F. Selheim, S. O. Døskeland, A. R. L. Gear, and H. Holmsen, "Protein kinase A mediates inhibition of the thrombin-induced platelet shape change by nitric oxide," Blood, vol. 104, no. 9, pp. 2775-2782, 2004.

[46] W. Zhang and R. W. Colman, "Thrombin regulates intracellular cyclic AMP concentration in human platelets through phosphorylation/activation of phosphodiesterase 3A," Blood, vol. 110, no. 5, pp. 1475-1482, 2007.

[47] M. A. H. Feijge, K. Ansink, K. Vanschoonbeek, and J. W. M. Heemskerk, "Control of platelet activation by cyclic AMP turnover and cyclic nucleotide phosphodiesterase type-3," Biochemical Pharmacology, vol. 67, no. 8, pp. 1559-1567, 2004.

[48] R. F. Storey, H. M. Judge, R. G. Wilcox, and S. Heptinstall, "Inhibition of ADP-induced P-selectin expression and plateletleukocyte conjugate formation by clopidogrel and the P2Y12 receptor antagonist AR-C69931MX but not aspirin," Thrombosis and Haemostasis, vol. 88, no. 3, pp. 488-494, 2002.

[49] Y. Ozeki, H. Ito, Y. Nagamura, F. Unemi, and T. Igawa, "12(S)HETE plays a role as a mediator of expression of platelet CD62 (P-selectin)," Platelets, vol. 9, no. 5, pp. 297-302, 1998.

[50] P. Bogaty, J. M. Brophy, M. Noel et al., "Impact of prolonged cyclooxygenase- 2 inhibition on inflammatory markers and endothelial function in patients with ischemic heart disease and raised C-reactive protein: a randomized placebo-controlled study," Circulation, vol. 110, no. 8, pp. 934-939, 2004.

[51] S. Srinivasan, F. Mir, J.-S. Huang, F. T. Khasawneh, S. C.-T. Lam, and G. C. Le Breton, "The P2Y12 antagonists, 2-methylthioadenosine $5^{\prime}$-monophosphate triethylammonium salt and cangrelor (ARC69931MX), can inhibit human platelet aggregation through a Gi-independent increase in cAMP levels," Journal of Biological Chemistry, vol. 284, no. 24, pp. 16108-16117, 2009.

[52] S. Suryadevara, M. Ueno, A. Tello-Montoliu et al., "Effects of pioglitazone on platelet P2Y12-mediated signalling in clopidogrel-treated patients with type 2 diabetes mellitus," Thrombosis and Haemostasis, vol. 108, pp. 930-936, 2012. 
[53] K. Andersen, M. Hurlen, H. Arnesen, and I. Seljeflot, "Aspirin non-responsiveness as measured by PFA-100 in patients with coronary artery disease," Thrombosis Research, vol. 108, no. 1, pp. 37-42, 2002.

[54] S. C. Fox, J. A. May, A. Shah, U. Neubert, and S. Heptinstall, "Measurement of platelet P-selectin for remote testing of platelet function during treatment with clopidogrel and/or aspirin," Platelets, vol. 20, no. 4, pp. 250-259, 2009.

[55] K. Nishijima, J. Kiryu, A. Tsujikawa et al., "Platelets adhering to the vascular wall mediate postischemic leukocyte-endothelial cell interactions in retinal microcirculation," Investigative Ophthalmology and Visual Science, vol. 45, no. 3, pp. 977-984, 2004.

[56] S. P. Jackson, W. S. Nesbitt, and E. Westein, "Dynamics of platelet thrombus formation," Journal of Thrombosis and Haemostasis, vol. 7, no. 1, pp. 17-20, 2009.

[57] S. Zoungas, B. P. McGrath, P. Branley et al., "Cardiovascular Morbidity and Mortality in the Atherosclerosis and Folic Acid Supplementation Trial (ASFAST) in chronic renal failure: a multicenter, randomized, controlled trial," Journal of the American College of Cardiology, vol. 47, no. 6, pp. 1108-1116, 2006.

[58] F. B. Hu, "Plant-based foods and prevention of cardiovascular disease: an overview," American Journal of Clinical Nutrition, vol. 78, pp. 544S-551S, 2003.

[59] E. J. Fuentes, L. A. Astudillo, M. I. Gutiérrez et al., "Fractions of aqueous and methanolic extracts from tomato (Solanum lycopersicum L.) present platelet antiaggregant activity," Blood Coagulation and Fibrinolysis, vol. 23, no. 2, pp. 109-117, 2012.

[60] M. R. Adams, D. L. Golden, H. Chen, T. C. Register, and E. T. Guggery, "A diet rich in green and yellow vegetables inhibits atherosclerosis in mice," Journal of Nutrition, vol. 136, no. 7, pp. 1886-1889, 2006.

[61] S. Pierre, L. Crosbie, and A. K. Duttaroy, "Inhibitory effect of aqueous extracts of some herbs on human platelet aggregation in vitro," Platelets, vol. 16, no. 8, pp. 469-473, 2005.

[62] C. Torres-Urrutia, L. Guzmán, G. Schmeda-Hirschmann et al., "Antiplatelet, anticoagulant, and fibrinolytic activity in vitro of extracts from selected fruits and vegetables," Blood Coagulation and Fibrinolysis, vol. 22, no. 3, pp. 197-205, 2011.

[63] A. K. Duttaroy and A. Jørgensen, "Effects of kiwi fruit consumption on platelet aggregation and plasma lipids in healthy human volunteers," Platelets, vol. 15, no. 5, pp. 287-292, 2004.

[64] A. Naemura, T. Mitani, Y. Ijiri et al., "Anti-thrombotic effect of strawberries," Blood Coagulation and Fibrinolysis, vol. 16, no. 7, pp. 501-509, 2005.

[65] A. Naemura, H. Ohira, M. Ikeda, K. Koshikawa, H. Ishii, and J. Yamamoto, "An experimentally antithrombotic strawberry variety is also effective in humans," Pathophysiology of Haemostasis and Thrombosis, vol. 35, no. 5, pp. 398-404, 2007.

[66] K. S. Osmont, C. R. Arnt, and I. L. Goldman, "Temporal aspects of onion-induced antiplatelet activity," Plant Foods for Human Nutrition, vol. 58, no. 1, pp. 27-40, 2003.

[67] H. Fukao, H. Yoshida, Y.-I. Tazawa, and T. Hada, "Antithrombotic effects of odorless garlic powder both in vitro and in vivo," Bioscience, Biotechnology and Biochemistry, vol. 71, no. 1, pp. 8490, 2007.

[68] P. F. Cavagnaro, A. Camargo, C. R. Galmarini, and P. W. Simon, "Effect of cooking on garlic (Allium sativum L.) antiplatelet activity and thiosulfinates content," Journal of Agricultural and Food Chemistry, vol. 55, no. 4, pp. 1280-1288, 2007.

[69] D. Sabha, B. Hiyasat, K. Grötzinger et al., "Allium ursinum L.: bioassay-guided isolation and identification of a galactolipid and a phytosterol exerting antiaggregatory effects," Pharmacology, vol. 89, no. 5-6, pp. 260-269, 2012.

[70] S. S. Chang, V. S. Lee, and Y. L. Tseng, "Gallic acid attenuates platelet activation and platelet-leukocyte aggregation: involving pathways of Akt and GSK3beta," Evidence-Based Complementary and Alternative Medicine, vol. 2012, Article ID 683872, 8 pages, 2012.

[71] J. A. Guerrero, M. L. Lozano, J. Castillo, O. Benavente-García, V. Vicente, and J. Rivera, "Flavonoids inhibit platelet function through binding to the thromboxane $\mathrm{A}_{2}$ receptor," Journal of Thrombosis and Haemostasis, vol. 3, no. 2, pp. 369-376, 2005.

[72] E. Fuentes, M. Alarcon, L. Astudillo et al., "Protective mechanisms of guanosine from Solanum lycopersicum on agonistinduced platelet activation: role of sCD40L," Molecules, vol. 18, pp. 8120-8135, 2013.

[73] J. B. Park, "5-Caffeoylquinic acid and caffeic acid orally administered suppress P-selectin expression on mouse platelets," Journal of Nutritional Biochemistry, vol. 20, no. 10, pp. 800-805, 2009.

[74] E. Fuentes, R. Castro, and L. Astudillo, "Bioassay-guided isolation and HPLC determination of bioactive compound that relate to the antiplatelet activity (adhesion, secretion, and aggregation) from Solanum lycopersicum," Evidence-Based Complementary and Alternative Medicine, vol. 2012, Article ID 147031, 10 pages, 2012.

[75] J. Wang, Z.-G. Huang, H. Cao et al., "Screening of anti-platelet aggregation agents from Panax notoginseng using human platelet extraction and HPLC-DAD-ESI-MS/MS," Journal of Separation Science, vol. 31, no. 6-7, pp. 1173-1180, 2008.

[76] G. Anfossi, I. Russo, P. Massucco et al., "Adenosine increases human platelet levels of cGMP through nitric oxide-possible role in its antiaggregating effect," Thrombosis Research, vol. 105, no. 1, pp. 71-78, 2002.

[77] T. Minamino, M. Kitakaze, H. Asanuma et al., "Endogenous adenosine inhibits P-selectin-dependent formation of coronary thromboemboli during hypoperfusion in dogs," Journal of Clinical Investigation, vol. 101, no. 8, pp. 1643-1653, 1998.

[78] J. B. Park, "Caffedymine from cocoa has COX inhibitory activity suppressing the expression of a platelet activation marker, Pselectin," Journal of Agricultural and Food Chemistry, vol. 55, no. 6, pp. 2171-2175, 2007.

[79] J. B. Park, "N-coumaroyldopamine and N-caffeoyldopamine increase cAMP via beta 2-adrenoceptors in myelocytic U937 cells," FASEB Journal, vol. 19, no. 6, pp. 497-502, 2005.

[80] J. B. Park and N. Schoene, "Clovamide-type phenylpropenoic acid amides, $\mathrm{N}$-coumaroyldopamine and $\mathrm{N}$-caffeoyldopamine, inhibit platelet-leukocyte interactions via suppressing Pselectin expression," Journal of Pharmacology and Experimental Therapeutics, vol. 317, no. 2, pp. 813-819, 2006.

[81] T. Takahashi and M. Miyazawa, "N-Caffeoyl serotonin as selective COX-2 inhibitor," Bioorganic and Medicinal Chemistry Letters, vol. 22, no. 7, pp. 2494-2496, 2012.

[82] H.-J. Cho, J. Y. Cho, M. H. Rhee, and H.-J. Park, “Cordycepin (3'-deoxyadenosine) inhibits human platelet aggregation in a cyclic AMP- and cyclic GMP-dependent manner," European Journal of Pharmacology, vol. 558, no. 1-3, pp. 43-51, 2007.

[83] H. J. Cho, J. Y. Cho, M. H. Rhee, C. R. Lim, and H. J. Park, "Cordycepin ( $3^{\prime}$-deoxyadenosine) inhibits human platelet aggregation induced by U46619, a TXA2 analogue," Journal of Pharmacy and Pharmacology, vol. 58, no. 12, pp. 1677-1682, 2006.

[84] B. H. Shah, Z. Nawaz, S. A. Pertani et al., "Inhibitory effect of curcumin, a food spice from turmeric, on platelet-activating 
factor- and arachidonic acid-mediated platelet aggregation through inhibition of thromboxane formation and $\mathrm{Ca}^{2+}$ signaling," Biochemical Pharmacology, vol. 58, no. 7, pp. 1167-1172, 1999.

[85] K. C. Srivastava, A. Bordia, and S. K. Verma, "Curcumin, a major component of food spice turmeric (Curcuma longa) inhibits aggregation and alters eicosanoid metabolism in human blood platelets," Prostaglandins Leukotrienes and Essential Fatty Acids, vol. 52, no. 4, pp. 223-227, 1995.

[86] L. Zhang, Z.-L. Gu, Z.-H. Qin, and Z.-Q. Liang, "Effect of curcumin on the adhesion of platelets to brain microvascular endothelial cells in vitro," Acta Pharmacologica Sinica, vol. 29, no. 7, pp. 800-807, 2008.

[87] A. M. Siddiqui, X. Cui, R. Wu et al., "The anti-inflammatory effect of curcumin in an experimental model of sepsis is mediated by up-regulation of peroxisome proliferator-activated receptor- $\gamma$," Critical Care Medicine, vol. 34, no. 7, pp. 1874-1882, 2006.

[88] H.-F. Chiu, S.-P. Yang, Y.-L. Kuo, Y.-S. Lai, and T.-C. Chou, "Mechanisms involved in the antiplatelet effect of C-phycocyanin," British Journal of Nutrition, vol. 95, no. 2, pp. 435-440, 2006.

[89] G. Hsiao, P. O.-H. Chou, M.-Y. Shen, D.-S. Chou, C.-H. Lin, and J.-R. Sheu, "C-phycocyanin, a very potent and novel platelet aggregation inhibitor from Spirulina platensis," Journal of Agricultural and Food Chemistry, vol. 53, no. 20, pp. 7734-7740, 2005.

[90] S.-M. Yu, C.-C. Chen, F.-N. Ko, Y.-L. Huang, T.-F. Huang, and C.-M. Teng, "Dicentrine, a novel antiplatelet agent inhibiting thromboxane formation and increasing the cyclic AMP level of rabbit platelets," Biochemical Pharmacology, vol. 43, no. 2, pp. 323-329, 1992.

[91] W.-J. Ok, H.-J. Cho, H.-H. Kim et al., "Epigallocatechin-3gallate has an anti-platelet effect in a cyclic AMP-dependent manner," Journal of Atherosclerosis and Thrombosis, vol. 19, no. 4, pp. 337-348, 2012.

[92] G. Hsiao, C.-Y. Chang, M.-Y. Shen et al., " $\alpha$-Naphthoflavone, a potent antiplatelet flavonoid, is mediated through inhibition of phospholipase C activity and stimulation of cyclic GMP formation," Journal of Agricultural and Food Chemistry, vol. 53, no. 13, pp. 5179-5186, 2005.

[93] F.-N. Ko, Y.-S. Lee, T.-S. Wu, and C.-M. Teng, "Inhibition of cyclooxygenase activity and increase in platelet cyclic AMP by girinimbine, isolated from Murraya euchrestifolia," Biochemical Pharmacology, vol. 48, no. 2, pp. 353-360, 1994.

[94] Y.-R. Jin, X.-H. Han, Y.-H. Zhang et al., "Antiplatelet activity of hesperetin, a bioflavonoid, is mainly mediated by inhibition of PLC- $\gamma 2$ phosphorylation and cyclooxygenase-1 activity," Atherosclerosis, vol. 194, no. 1, pp. 144-152, 2007.

[95] M. C. Chang, B. J. Uang, C. Y. Tsai et al., "Hydroxychavicol, a novel betel leaf component, inhibits platelet aggregation by suppression of cyclooxygenase, thromboxane production and calcium mobilization," British Journal of Pharmacology, vol. 152, no. 1, pp. 73-82, 2007.

[96] C. Y. Shih and T. C. Chou, "The antiplatelet activity of magnolol is mediated by PPAR-beta/gamma," Biochemical Pharmacology, vol. 84, pp. 793-803, 2012.

[97] M. C. Chang, H. H. Chang, C. P. Chan et al., "Antiplatelet effect of phloroglucinol is related to inhibition of cyclooxygenase, reactive oxygen species, ERK/p38 signaling and thromboxane $\mathrm{A}_{2}$ production," Toxicology and Applied Pharmacology, vol. 263, pp. 287-295, 2012.
[98] W. J. Oh, M. Endale, and S. C. Park, "Dual roles of quercetin in platelets: phosphoinositide-3-kinase and MAP kinases inhibition, and CAMP-dependent vasodilator-stimulated phosphoprotein stimulation," Evidence-Based Complementary and Alternative Medicine, vol. 2012, Article ID 485262, 10 pages, 2012.

[99] J.-H. Jeng, H.-L. Wu, B.-R. Lin et al., "Antiplatelet effect of sanguinarine is correlated to calcium mobilization, thromboxane and cAMP production," Atherosclerosis, vol. 191, no. 2, pp. 250 258, 2007.

[100] C. C. Chang, W. J. Lu, C. W. Chiang et al., "Potent antiplatelet activity of sesamol in an in vitro and in vivo model: pivotal roles of cyclic AMP and p38 mitogen-activated protein kinase," Journal of Nutritional Biochemistry, vol. 21, no. 12, pp. 1214-1221, 2010.

[101] C.-C. Chang, W.-J. Lu, E.-T. Ong et al., "A novel role of sesamol in inhibiting NF-B-mediated signaling in platelet activation," Journal of Biomedical Science, vol. 18, no. 1, article 93, 2011.

[102] T. Jayakumar, W. F. Chen, W. J. Lu et al., "A novel antithrombotic effect of sulforaphane via activation of platelet adenylate cyclase: ex vivo and in vivo studies," Journal of Nutritional Biochemistry, 2012.

[103] W. Y. Chuang, P. H. Kung, C. Y. Kuo, and C. C. Wu, "Sulforaphane prevents human platelet aggregation through inhibiting the phosphatidylinositol 3-kinase/Akt pathway," Thrombosis \& Haemostasis, vol. 109, no. 6, pp. 1120-1130, 2013.

[104] T.-C. Chou, C.-Y. Shih, and Y.-T. Chen, "Inhibitory effect of $\alpha$ Lipoic acid on platelet aggregation is mediated by PPARs," Journal of Agricultural and Food Chemistry, vol. 59, no. 7, pp. 30503059, 2011.

[105] Y.-S. Lai, C.-Y. Shih, Y.-F. Huang, and T.-C. Chou, "Antiplatelet activity of $\alpha$-Lipoic acid," Journal of Agricultural and Food Chemistry, vol. 58, no. 15, pp. 8596-8603, 2010.

[106] W. L. Stone, K. Krishnan, S. E. Campbell, M. Qui, S. G. Whaley, and H. Yang, "Tocopherols and the treatment of colon cancer," Annals of the New York Academy of Sciences, vol. 1031, pp. 223233, 2004.

[107] S. E. Campbell, W. L. Stone, S. G. Whaley, M. Qui, and K. Krishnan, "Gamma $(\gamma)$ tocopherol upregulates peroxisome proliferator activated receptor (PPAR) gamma $(\gamma)$ expression in SW 480 human colon cancer cell lines," BMC Cancer, vol. 3, article 25, 2003.

[108] J. E. Freedman, J. H. Farhat, J. Loscalzo, and J. F. Keaney Jr., “ $\alpha$ Tocopherol inhibits aggregation of human platelets by a protein kinase C-dependent mechanism," Circulation, vol. 94, no. 10, pp. 2434-2440, 1996.

[109] T. Murohara, H. Ikeda, Y. Otsuka et al., "Inhibition of platelet adherence to mononuclear cells by $\alpha$-tocopherol: role of Pselectin," Circulation, vol. 110, no. 2, pp. 141-148, 2004.

[110] N. Gitlin, N. L. Julie, C. L. Spurr, K. N. Lim, and H. M. Juarbe, "Two cases of severe clinical and histologic hepatotoxicity associated with troglitazone," Annals of Internal Medicine, vol. 129, no. 1, pp. 36-38, 1998.

[111] I. Palomo, E. Leiva, and M. Vásquez, Dieta Mediterranea: Prevención de las Enfermeda des Cardiovasculares, Universidad de Talca Press, Talca, Chile, 2007.

[112] N. K. Salam, T. H.-W. Huang, B. P. Kota, M. S. Kim, Y. Li, and D. E. Hibbs, "Novel PPAR-gamma agonists identified from a natural product library: a virtual screening, induced-fit docking and biological assay study," Chemical Biology and Drug Design, vol. 71, no. 1, pp. 57-70, 2008.

[113] N. Takahashi, T. Kawada, T. Goto et al., "Dual action of isoprenols from herbal medicines on both PPAR $\gamma$ and PPAR $\alpha$ in 
3T3-L1 adipocytes and HepG2 hepatocytes," FEBS Letters, vol. 514, no. 2-3, pp. 315-322, 2002.

[114] A. Pawar and D. B. Jump, "Unsaturated fatty acid regulation of peroxisome proliferator-activated receptor $\alpha$ activity in rat primary hepatoctes," Journal of Biological Chemistry, vol. 278, no. 38, pp. 35931-35939, 2003.

[115] F. S. El-Feraly and Y. M. Chan, "Isolation and characterization of the sesquiterpene lactones costunolide, parthenolide, costunolide diepoxide, santamarine, and reynosin from Magnolia grandiflora L," Journal of Pharmaceutical Sciences, vol. 67, no. 3, pp. 347-350, 1978.

[116] C.-C. Shen, C.-L. Ni, Y.-C. Shen et al., "Phenolic constituents from the stem bark of Magnolia officinalis," Journal of Natural Products, vol. 72, no. 1, pp. 168-171, 2009.

[117] S.-S. Choi, B.-Y. Cha, Y.-S. Lee et al., "Magnolol enhances adipocyte differentiation and glucose uptake in 3T3-L1 cells," Life Sciences, vol. 84, no. 25-26, pp. 908-914, 2009.

[118] E. W. Holy, M. Forestier, E. K. Richter et al., "Dietary $\alpha$-linolenic acid inhibits arterial thrombus formation, tissue factor expression, and platelet activation," Arteriosclerosis, Thrombosis, and Vascular Biology, vol. 31, no. 8, pp. 1772-1780, 2011.

[119] H. Yokoi, H. Mizukami, A. Nagatsu, H. Tanabe, and M. Inoue, "Hydroxy monounsaturated fatty acids as agonists for peroxisome proliferator-activated receptors," Biological and Pharmaceutical Bulletin, vol. 33, no. 5, pp. 854-861, 2010.

[120] J. B. Park, "Isolation and characterization of N-feruloyltyramine as the p-selectin expression suppressor from garlic (Allium sativum)," Journal of Agricultural and Food Chemistry, vol. 57, no. 19, pp. 8868-8872, 2009.

[121] T. C. Reddy, P. Aparoy, N. K. Babu, K. A. Kumar, S. K. Kalangi, and P. Reddanna, "Kinetics and docking studies of a COX-2 inhibitor isolated from terminalia bellerica fruits," Protein and Peptide Letters, vol. 17, no. 10, pp. 1251-1257, 2010.

[122] C. C. M. Appeldoorn, A. Bonnefoy, B. C. H. Lutters et al., "Gallic acid antagonizes P-selectin-mediated platelet-leukocyte interactions: implications for the French paradox," Circulation, vol. 111, no. 1, pp. 106-112, 2005.

[123] N. Cook, S. R. Nahorski, C. Jagger, and D. B. Barnett, "Is the human platelet beta2 adrenoceptor coupled to adenylate cyclase?" Naunyn-Schmiedeberg's Archives of Pharmacology, vol. 337, no. 2, pp. 238-240, 1988.

[124] S.-H. Kim, C.-D. Jun, K. Suk et al., "Gallic acid inhibits histamine release and pro-inflammatory cytokine production in mast cells," Toxicological Sciences, vol. 91, no. 1, pp. 123-131, 2006.

[125] H. J. Cho, H. J. Kang, Y. J. Kim et al., "Inhibition of platelet aggregation by chlorogenic acid via cAMP and cGMP-dependent manner," Blood Coagul Fibrinolysis, vol. 23, pp. 629-635, 2012.

[126] N. J. Kang, K. W. Lee, B. J. Shin et al., "Caffeic acid, a phenolic phytochemical in coffee, directly inhibits Fyn kinase activity and UVB-induced COX-2 expression," Carcinogenesis, vol. 30, no. 2, pp. 321-330, 2009.

[127] L. Yu, Y. Li, H. Fan, J. Duan, Q. Zhu, and S. Li, "Analysis of marker compounds with anti-platelet aggregation effects in mailuoning injection using platelet binding assay combined with HPLC-DAD-ESI-MS and solid-phase extraction technique," Phytochemical Analysis, vol. 22, no. 1, pp. 87-93, 2011.

[128] D. C. Sloan and R. J. Haslam, "Protein kinase C-dependent and $\mathrm{Ca}^{2+}$-dependent mechanisms of secretion from streptolysin 0 permeabilized platelets: effects of leakage of cytosolic proteins," Biochemical Journal, vol. 328, no. 1, pp. 13-21, 1997.
[129] M. B. Feinstein and C. Fraser, "Human platelet secretion and aggregation induced by calcium ionophores. Inhibition by PGE1 and dibutyryl cyclic AMP," Journal of General Physiology, vol. 66, no. 5, pp. 561-581, 1975.

[130] P.-G. Li, L. Sun, X. Han, S. Ling, W.-T. Gan, and J.-W. Xu, "Quercetin induces rapid eNOS phosphorylation and vasodilation by an Akt-independent and PKA-dependent mechanism," Pharmacology, vol. 89, no. 3-4, pp. 220-228, 2012.

[131] D. Yang, H. Chen, M. Koupenova et al., "A new role for the A2b adenosine receptor in regulating platelet function," Journal of Thrombosis and Haemostasis, vol. 8, no. 4, pp. 817-827, 2010.

[132] S. Loyau, B. Dumont, V. Ollivier et al., "Platelet glycoprotein VI dimerization, an active process inducing receptor competence, is an indicator of platelet reactivity," Arteriosclerosis, Thrombosis, and Vascular Biology, vol. 32, no. 3, pp. 778-785, 2012. 


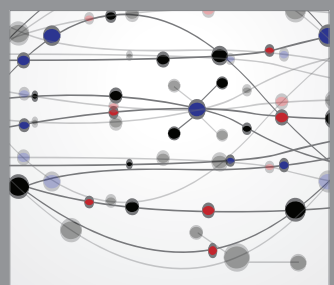

The Scientific World Journal
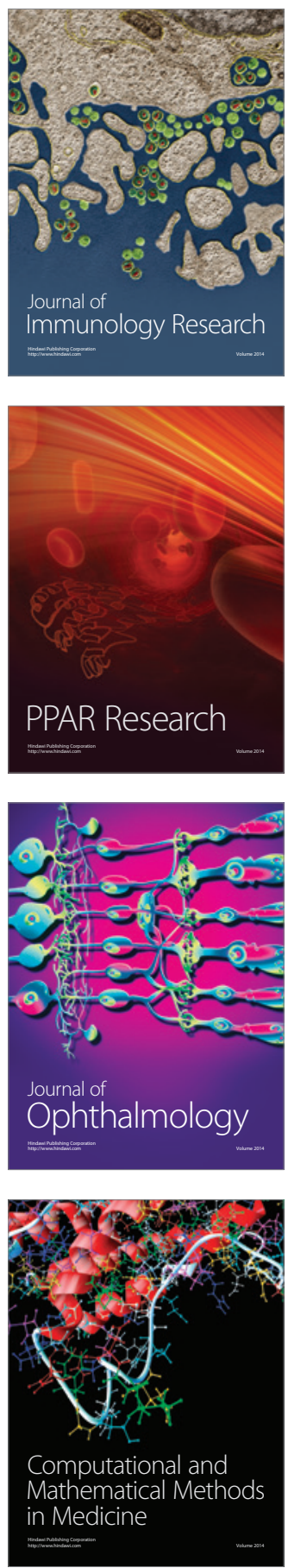

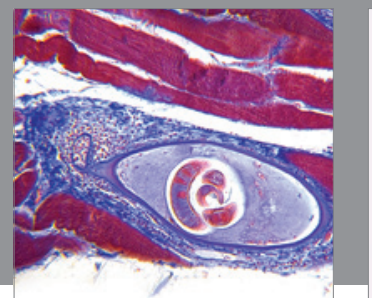

Gastroenterology

Research and Practice
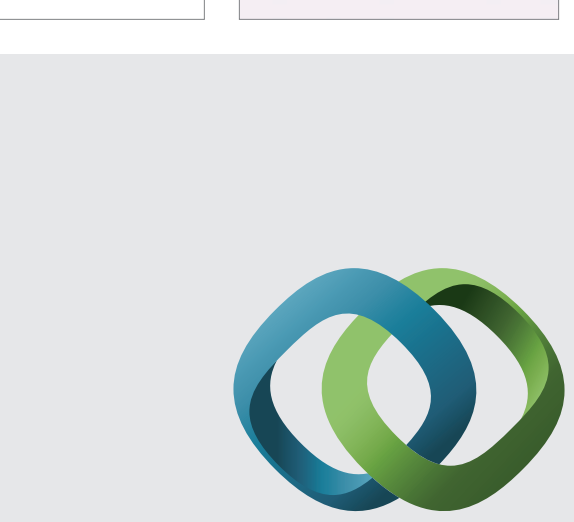

\section{Hindawi}

Submit your manuscripts at

http://www.hindawi.com
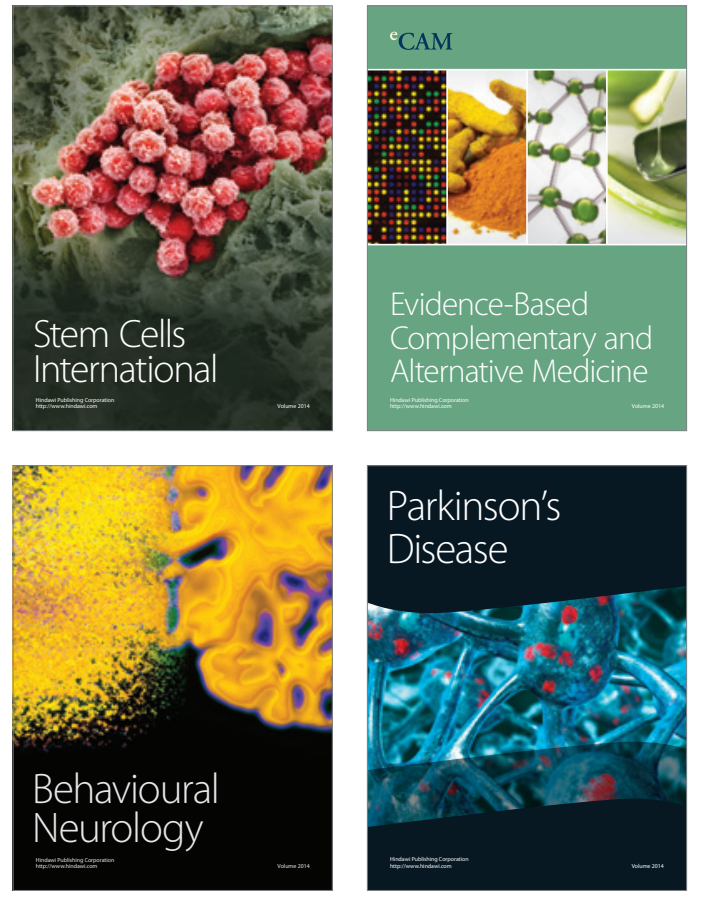
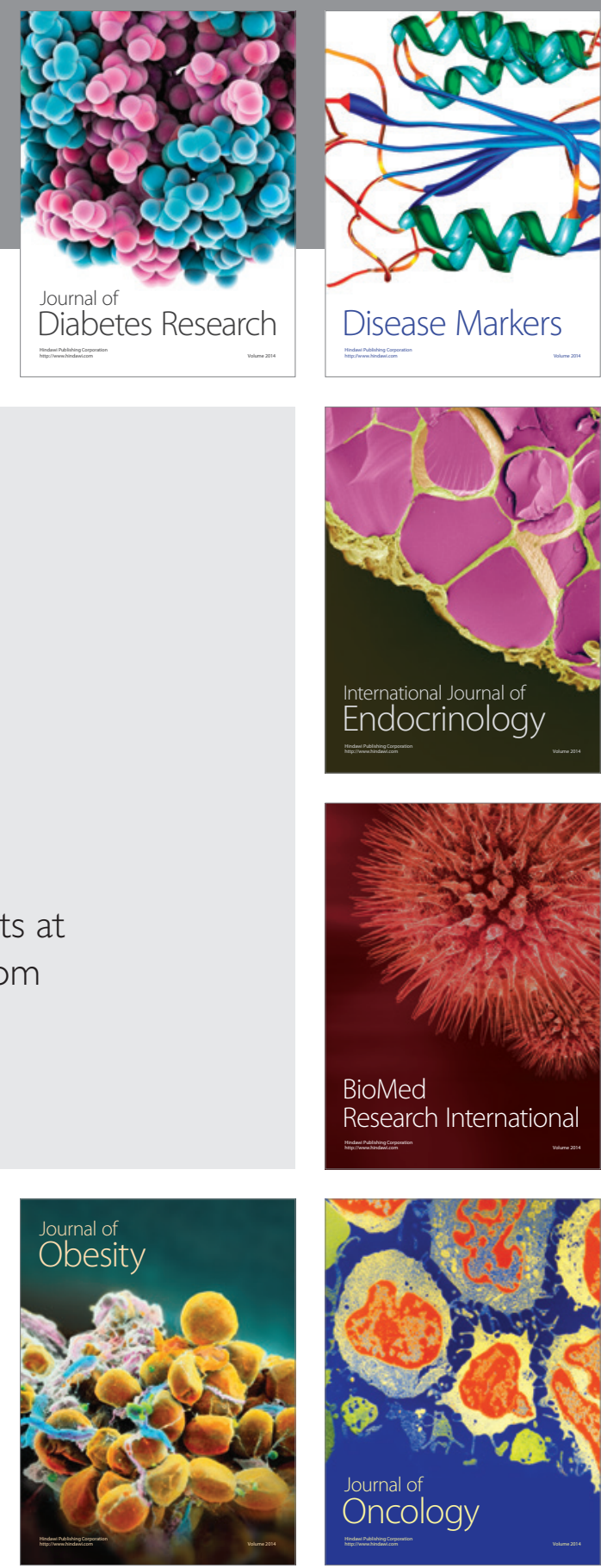

Disease Markers
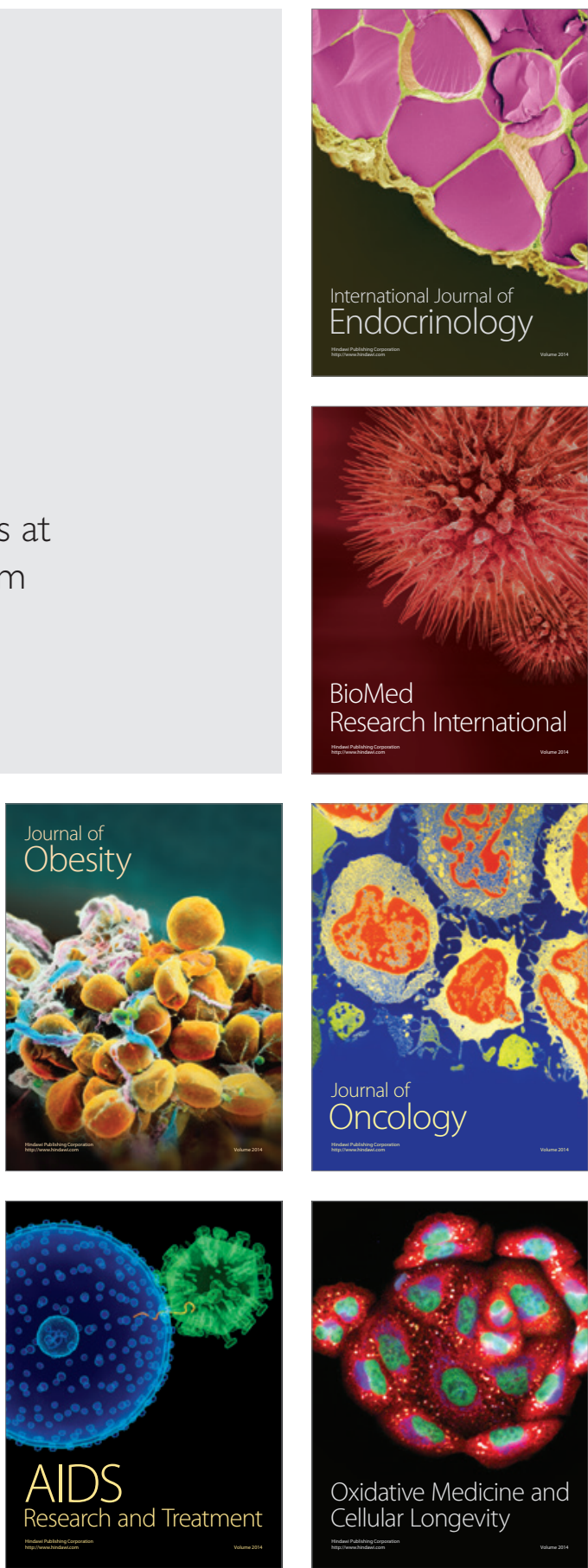